\title{
USE OF CASWELL'S CLASSIFICATION ON FOOD QUALITY ATTRIBUTES TO ASSESS CONSUMER PERCEPTIONS TOWARDS FRESH MILK IN TETRA-PACKED CONTAINERS
}

\author{
S.Kariyawasam ${ }^{1}$, U. Jayasinghe-Mudalige ${ }^{2}$ and J. Weerahewa ${ }^{3}$
}

\begin{abstract}
This study assesses, using the Caswell's classification on food quality attributes (1998), what quality attributes that consumers consider most important in their decision to purchase fresh milk stored in tetra-pack containers, and the impact of a number of socio-economic characteristics of consumers on this behavior. A consumer survey was carried out $(n=664)$ in the Gampaha district from April to May in 2005, and data pertaining to 100 who consume it with the highest frequency (i.e. 3.43 packs/week) were considered for the empirical analysis. The results based on two indices, namely the "Mean Score of Quality Attribute" (MSQA) and the "Food Quality Responsive Index" (FQRI) suggest that attributes such as purity, appearance, size, convenience, and informational labeling from "value" and "package" subsets were the most important. It also shows that consumers did not judge that tetra-packs enhance attributed included in the "food safety" and "nutrition" subsets to a larger extent. The statistic outcome based on Ordered Logistic regression techniques, where the values of FQRI were used to develop four dependent variables, shows that factors such as age, marital status, sex, and level of education and income of a consumer have a significant impact on this behavior. The results suggest that the market can work effectively on promoting the sales of fresh milk by enhancing its quality in terms of value and packaging attributes, while the government should take into account of regulating the attributes of food safety and nutrition through appropriate food standards.
\end{abstract}

Key words: Caswell's classification on food quality, Consumer perceptions, Food packaging, Food safety, Milk processing sector, Nutrition, Tetra-pack

\section{INTRODUCTION}

Assuring the quality of food products has become an increasing focus for governments in both developed and developing countries, food processing firms, and international trade and standards bodies. The higher valuation given to certain attributes of food quality prompts implementation of enhanced quality assurance systems by food companies voluntarily. Not only that, but respective governments also come up with more regulation to regulate the industry (Caswell, 1998).
Product quality itself is multidimensional, and as a result, national level regulation aiming quality of food products takes on many dimensions or regimes. There is no definitive list of all attributes of quality, because the importance of such characteristics varies across circumstances and among customers. Quality management literature, in more general perspective, explores a number of attributes for product quality. According to Garvin (1987), product quality has eight dimensions, including

${ }^{1}$ Final Year Student, Department of Agribusiness Management, Faculty of Agriculture and 43 Plantation Management, Wayamba University of Sri Lanka, Makandura, Gonawila (NWP), Sri Lanka. ${ }^{2}$ Senior Lecturer, Department of Agribusiness Management, Faculty of Agriculture and Plantation Management, Wayamba University of Sri Lanka, Makandura, Gonawila (NWP), Sri Lanka.

${ }^{3}$ Assistant Professor, Department of Food, Agriculture, and Resource Economics, University of Guelph, Guelph, Ontario, N1G 2W1, Canada. 
performance, features, reliability, conformance, durability, serviceability, aesthetics and perceptions. Brown et al. (1994) specifies a number of indicators to measure quality including, product service quality, operational quality, financial quality, public responsibility, employee and customer satisfaction, where each indicator can be measured by means of a subset of another variables, for example, employee satisfaction is a function of turnover, request for transfer, complaints, and absenteeism.

A number of conceptual frameworks and theoretical models have been developed to characterize consumer behaviour on food quality attributes that used different dimensions (see for example, Caswell, 1992; Caswell and Mojduszka, 1996; Caswell and Padberg, 1992; Frazao and Allshouse, 1996; French and Neighbors, 1991).

Some of which were based on the environment where the consumers receive and process information (i.e. "information environment"), while other set of papers used the concept of "vertical and horizontal differentiation" - the fact that how buyers share certain attributes of quality was taken into account. In so doing, "vertical" is referred to the cases where buyers all share the same quality ranking, and "horizontal" is referred to the cases where buyers have different quality rankings (see Caswell, 1998 for details).

Nelson (1970, 1974) and Darby and Karni (1973), for example distinguished three categories of product quality attributes that explain how consumers learn about the quality of the commodities they purchase. Of which, the first category is referred as "search" attributes where the consumers can determine product quality at the point of purchase by looking at the product, examining, or researching it (e.g., color). For the products that belong to the second category - called as "experience" attributes - consumers cannot determine product quality until they buy it and use it (e.g., taste). In connection with the products that belong to the third category "credence" attributes - consumers cannot judge the quality of a product even after consumption of it (e.g., pesticide residues). Certain other frameworks used the concept of "intrinsic or extrinsic" nature of an attribute of quality, and a number of different intrinsic attributes of food quality, as identified by Caswell (1998), are described in Table 01.

Consumers who judge the quality of different products may do so based on different criteria. For example, certain consumers may consider food safety as the most important subset of food quality (Hooker and Caswell, 1998). On the other hand, a consumer who purchases a Genetically Modified (GM) food product may care, first and foremost, about the use of biotechnology, and in turn, accept or reject the purchase of that product on the basis of intrinsic process attributes. Moreover, a consumer who is much worried about the presence of GM food may also care about other quality attributes associated with that such as environmental impact, nutritional quality, and convenience of use. Consequently, they will make tradeoffs, particularly if safety is assured, between the GM status of the food and other desirable attributes (Caswell, 1998). 
Table 01: Intrinsic food quality attributes categorized under four subsets.

\begin{tabular}{|c|c|c|c|}
\hline Food Safety & Nutritional & Value & Package \\
\hline 1.1 Foodborne Pathogen & 2.1 Calories & 3.1 Purity & 4.1 Package Material \\
\hline 1.2 Heavy Metal & 2.2 Fat \& Cholesterol & $\begin{array}{l}3.2 \text { Compositional } \\
\text { Integrity }\end{array}$ & $\begin{array}{l}\text { 4.2 Other Information (e.g. } \\
\text { Handling / Cooking } \\
\text { Instructions) }\end{array}$ \\
\hline 1.3 Pesticides Residues & 2.3 Minerals & 3.3 Appearance & $\begin{array}{l}\text { 4.3 Labeling (e.g. } \\
\text { Nutritional) }\end{array}$ \\
\hline 1.4 Food Additives & 2.4 Carbohydrates & 3.4 Taste & \\
\hline $\begin{array}{l}\text { 1.5 Naturally Occurring } \\
\text { Toxins }\end{array}$ & 2.5 Protein & 3.5 Convenience & \\
\hline 1.6 Veterinary Residues & 2.6 Vitamins & 3.6 Size and Style & \\
\hline
\end{tabular}

(Source: Caswell (1998))

However, to the best knowledge of authors, there was no empirical investigation carried out to date that investigated the applicability of Caswell's classification on food quality from the consumers point of view. In fact, there is a paucity in the food economics literature in the context of consumer base in Sri Lanka that explore the relative importance of a given quality attribute or a bundle of attributes (i.e. a subset) to a consumer to purchase a particular food product.

This study examined empirically that economic problem, where the consumer perceptions regarding various quality attributes pertaining to "fresh milk stored in a $350 \mathrm{ml}$ tetrapacked container" (FMTP) was taken as the special case. Tetra-pack, which is coming under the category of laminates, is a relatively novel product to the Sri Lanka fresh milk market. It is an aseptic packaging system which has been sterilized prior to fill with sterilized food, resulting a product which is shelf stable for six months. It has been made out of three basic materials combined together, resulting a very efficient, safe and lightweight package. Each of this material has a unique function. It is made out of paper $(75 \%)$ to provide strength and stiffness, polythene (20\%) to make the packages liquid tight and provide a barrier to micro-organisms, aluminum foil $(5 \%)$ to keep out air, light, offflavors and all the things that can cause food to deteriorate. Fresh milk packages that come under these laminating packages (excluding plastic bottles or glass containers) are treated with Ultra High Temperature (UHT) treatment.

The specific objective of this study was, therefore, to examine empirically extent to which consumers that divert from consuming fresh milk stored in a "conventional" packaging material (e.g. glass bottles and plastic cans) to consume FMTP are perceived about its quality using the Caswell's classification, and impact of various socio-economic characteristics of a consumer (e.g. age, gender, income, marital status, and level of education) on this behaviour. 


\section{METHODS}

This section explains the hypothesis developed and the theoretical framework used to examine this problem empirically, and the methods used to collect and analyze data.

\section{The Hypotheses}

The fact that an assortment of food quality attributes were specified in the Caswell's classification (1998) as well as the subjective nature of these attributes as perceived by consumers, and in turn, the requirement that the individual attributes identified in the classification (see, Table 1) should not have any overlapping characteristics (i.e. mutually exclusive and exhaustive) were explicitly taken into account in developing an appropriate empirical framework to examine this economic problem. The following hypotheses were developed for the purpose of analysis:

1) A decision of a consumer to purchase FMTP regularly instead of spending that part of money on purchasing fresh milk that is stored in other packaging materials (e.g. glass bottles and plastic cans) is caused by the extra utility the consumer obtained on the perception that FMTP is better in quality with respect to:

i) a particular attribute/s (i.e. "relative importance" of an individual attribute such as Food additives, Cholesterol, Purity, and Size etc.), and/or

ii) all the attributes listed in the Caswell's classification (see, Table 1).

2) The decision of a consumer explained in (1) above is associated with the socio-economic characteristics of the consumer, including: (i) age; (ii) sex; (iii) disposable income; (iv) level of education, and (v) marital status.

\section{Indices to Reflect Consumer Perceptions on Food Quality Attributes}

However, as highlighted above, quantifying of such behavior is associated with a number of difficulties, including "unobservability" (Hair et al., 1995) and "subjectivity" (Buchanan, 1969) of perceptions amongst the individuals. To resolve the difficulties, researchers have resorted to alternative ways of developing appropriate techniques to avoid losing too much information. Powers and Xie (1999), for example, report that "Scoring Methods" can effectively be used to evaluate such criteria, and "Integer Scoring", which assigns integers a rank order is the simplest and perhaps most popular of these methods. In integer scoring, for example, the researcher can assign a Likert-like scale of strongly disagree $=$ 1 , disagree $=2$, neutral $=3$, agree $=$ 4 , and strongly agree $=5$ to measure the extent to which a respondent agrees on a given criteria. In doing so, the terms of the scale, and the range of the integers, may be set according to the nature of the question/issue. The crucial assumption underlying integer scoring is that the distances between adjacent categories are all equal, thus, researchers who may use integer scoring should be conscious of, and sensitive to, this.

Based on these principles, the scores given by respondents in a sample to a set of statements explaining the quality attributes listed in Table 1 was used to evaluate the first part of the Hypothesis (1), i.e. "relative importance" of each attribute to the respondents in a sample, on an average. For this purpose, a "Mean Score of Quality 
Attribute" (MSQA) was calculated by taking the aggregate scores given by respondents in the sample $\left(\mathrm{N}_{i}\right.$, where $i$ $=1,2 \ldots n)$ to all attributes $\left(\mathrm{X}_{S}\right.$, where $s$ $=1,2 \ldots m)$ and dividing it by number of respondents in the sample $\left(\mathrm{N}_{i}\right)$. The value of MSQA will, in turn, depend on the size of the scale that used to obtain scores. For example, the value of MSQA will be ranged from " 1 " (minimum) to " 5 " (maximum) when it takes using a five-point Likert scale, as used in this analysis. Based on this range, if any particular quality attribute gets a value of MSQA more than 2.5, it is an indication that consumers in the sample prefer FMTP than other substitutes(According to Powers and Xie (1999), the mid point in a five point Likert-scale (i.e. 2.5) demarcates changes to a preference from one choice to another (i.e. conventional to tetra-pack in this particular case)), since they believe that that particular attribute is best provided by the former than the later, and vise versa.

The values of MSQA was, subsequently, used to develop another index - namely the "Food Quality Responsive Index" (FQRI), which was useful in testing the second part of the Hypothesis (1), i.e. how important "all the attributes" listed under four subsets in the Caswell's classification for a consumer, as a whole, to be loyal with a given food product, and in this particular case FMTP. This will become an Additive Index, which can be estimated using the same techniques used to develop the MSQA. The formulation of the FQRI was based on the Equation shown below:
In this equation, the term $\mathrm{a}_{\text {is }}$ denotes the integer score given to an attribute $\left(\mathrm{X}_{\mathrm{s}}\right)$ by the respondent $i(i=1,2,3 \ldots \mathrm{n})$ on the Likert-scale and $s$ represents the number of attributes $(s=1,2,3 \ldots m)$ used to calculate the index. The scores given by respondents to $s$ where $m=$ 21 for this analysis (see, Table 1) were used to estimate the FQRI. The term $a \mathrm{X}$ represents the "Maximum Potential Score" that can be obtained by a respondent, which in turn be used to normalize the value of the index (e.g. given a set of 21 attributes with a fivepoint Likert-scale it would be $5 \times 21=$ 105).

With normalization of the index, the values should, theoretically, be ranged from 0 (minimum) to 1 (maximum) continuously with a certain Mean and Standard Deviation. Given the largely unknown behaviour of consumers with respect to each subset, all attributes shown in Table 1 were given equal weights in estimating the index. Thus, the simple average of Likert-scale values normalized by the maximum potential score $(\mathrm{aX})$ was taken to develop the index.

\section{Specification of the Empirical Model}

The following empirical model was constructed to find out whether there is any significant relationship between consumer perceptions on food quality attributes (i.e. FQRI as the dependent variable) and their socio-economic characteristics, i.e. to test the Hypothesis (2), in which explanatory variables are described in Table 02:

$$
F Q R I \quad{ }_{i}=\sum_{\mathrm{s}=1}^{\mathrm{m}} a_{i s} . \mathrm{X}_{s} / \mathrm{aX}
$$




$$
\mathrm{FQRI}_{\mathrm{i}}=\beta_{0}+\beta_{1} * \mathrm{AGE}_{\mathrm{i}}+\beta_{2} * \mathrm{SEX}_{\mathrm{i}}+\beta_{3} * \mathrm{INC}_{\mathrm{i}}+\beta_{4} * \mathrm{EDU}_{\mathrm{i}}+\beta_{5} * \mathrm{MRS}_{\mathrm{i}}+\varepsilon_{\mathrm{i}}
$$

Table 02: Description on variables in the model:

\begin{tabular}{|c|c|c|}
\hline Notation & Description & Categories \\
\hline AGE & Age of the consumer & $\begin{array}{l}1=\text { Less than } 35 \text { years } \\
0=\text { More than } 35 \text { years }\end{array}$ \\
\hline SEX & Type of gender of the consumer & $\begin{array}{l}1=\text { Male } \\
0=\text { Female }\end{array}$ \\
\hline INC & $\begin{array}{l}\text { Disposable income as a fraction of total } \\
\text { income }\end{array}$ & $\begin{array}{l}1=\text { More than } 0.75 \\
0=\text { Less than } 0.75\end{array}$ \\
\hline EDU & Level of education of the consumer & $\begin{array}{l}1=\text { Beyond the } \mathrm{O} / \mathrm{L} \\
0=\mathrm{Up} \text { to the } \mathrm{O} / \mathrm{L}\end{array}$ \\
\hline MRS & Marital status of the consumer & $\begin{array}{l}1=\text { Unmarried } \\
0=\text { Married }\end{array}$ \\
\hline
\end{tabular}

\section{Data Collection and Analysis}

A structured questionnaire, which was pilot tested with 30 consumers was used to collect the data during the April and May in 2005. It was administered with 664 consumers at 10 different marketplaces, including large-scale national chain stores, medium to small-scale grocery stores, and milk bars located in the Gampaha district. A kind of systematic sampling procedure was used to select consumers representing the socioeconomic characteristics indicated in the empirical model. For example, emphasis was given to maintain approximately $1: 1$ ratio of "Male : Female" within the sample, and to maintain 1:1 ratio of "Young : Old" within each sex category when contacting the consumers for the survey.

To develop the MSQA and FQRI, a set of statements explaining the meaning of individual quality attributes were forwarded to consumers through this questionnaire so that an average consumer can understand meaning and difference between each attribute properly. One such statement, for example was "I prefer fresh milk stored in a $350 \mathrm{ml}$ tetra-pack, because it contains low calorie per $100 \mathrm{ml}$ than fresh milk stored in a glass bottle or a plastic can". Another statement was: "foodborne pathogens that may be presence in fresh milk stored in a tetrapack is comparatively lower than those pathogens included in fresh milk stored in a glass bottle or a plastic can". The respondents were, in turn, asked to indicate their attitudes and perceptions about each statement on a five-point Likert scale ranging from: (1) "totally disagree"; (2) "disagree to some extent"; (3) "neither agree nor disagree"; (4) "agree to some extent", and (5) "totally agree" (Oppenheim, 1992). As can be seen in the statements given, there were certain modifications made in explaining the nature and characteristic of each quality attribute so as to reflect common perceptions of consumers and those in the society on these attributes and to avoid bias in judgments (e.g. "low" in fat / "high" in minerals / "high" in purity etc.). Also, the original questionnaire was administered in the "Sinhalese" language with a majority of respondents, and certain technical terms were duly explained by taking into account of knowledge of consumers with respect to certain attributes.

The Ordered Logistic Regression techniques were used to estimate the 
coefficients of the empirical model (Borooah, 2002 and Pampel, 2000). The FQRI derived for consumers in the sample $(n=100)$ were used to derive four-ordered dependent variables for the analysis. The estimates of "logged odds" (logits) of explanatory variables, especially their relative size and sign were used to interpret the nature and impact of which on the consumer perceptions on quality attributes.

\section{RESULTS AND DISCUSSION}

This section explains the descriptive statistics pertaining to the sample and two indices (MSQA and FSRI) and the outcome of the Ordered Logistic Regression analysis.

\section{Frequency of Consuming FMTP}

Amongst the 664 consumers participated to the study, those 100 consumers who used to consume FMTP with the "highest frequency" (i.e. number of $350 \mathrm{ml}$ packs per week) - "FMTP lovers" - were selected to the analysis (i.e. $15 \%$ consumers from the original ample). The Mean consumption of FMTP within this sub sample $(\mathrm{n}=100)$ was 3.43 tetra packs per week $($ Standard Deviation $=0.080)$ with the Minimum and Maximum values of 2.28 and 5.77 tetra packs per week, respectively. (Alternatively, the FMTP lovers could have been defined as those who drink more than 3 packs per week since it would consist of about $48 \%$ of the sample (i.e. $319 / 664$
* 100) (Figure 1). However, inclusion of 219 consumers (i.e. 319 - 100) into the sample whose frequency of consumption of tetra-packs fall within the range of 3.43 and 3.00 (i.e. 0.43 for 219 consumers) made the sample was biased towards them. When we take the first 100 consumers frequency of which were range from 5.77 to 3.43 (i.e. 2.34).)

\section{Descriptive Statistics of MSQA}

The Mean Scores of Quality Attributes (MSQA) calculated for every attribute in the Caswell's classification for FMTP lovers is reported in Table 03.

The results show that consumers' purchase FMTP over the fresh milk stored in other types of containers, because they believe that it is better in quality with respect to attributes included in "value" and "packaging" subsets. Interestingly, those attributes included in these two subsets were ranked within the "top 10" and their respective MSQA values were marked above 3.5. The "most important" quality attribute for the consumers to purchase FMTP is that they considered it is a better "packaging material" (4.73) to store milk in compared to others made up of glass and plastics. The facts that FMTP provides a better "appearance" (4.52) and it is "convenient" to use (i.e. transport / store) in their day-to-day life (4.42) were also considered as major factors. 


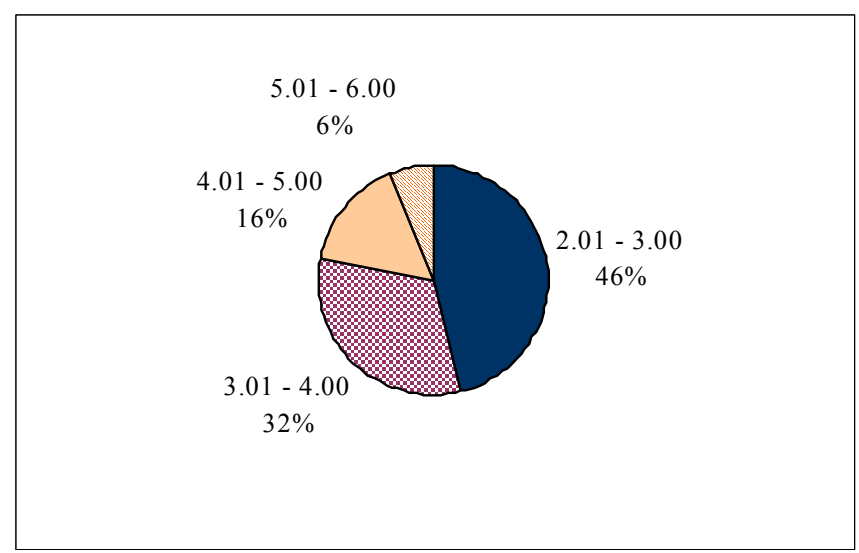

Figure 01: Number of FMTP consumed per week:

\section{Table 03: Descriptive Statistics of MAS:}

\begin{tabular}{clccc}
\hline Subset & Attribute & MSQA & $\begin{array}{c}\text { Rank } \\
\text { wlithin }\end{array}$ & $\begin{array}{c}\text { Rank as } \\
\text { 1. Food Salo }\end{array}$ \\
& 1.1 Low in Foodborne Pathogen & 3.25 & 1 & 10 \\
& 1.2 Low in Heavy Metal & 2.91 & 3 & 15 \\
& 1.3 Low in Pesticides Residues & 3.22 & 2 & 11 \\
& 1.4 Low in Food Additives & 2.36 & 6 & 21 \\
& 1.5 Low in Naturally Occurring Toxins & 2.75 & 5 & 18 \\
& 1.6 Low in Veterinary Residues & 2.87 & 4 & 16 \\
2. Nutritional & 2.1 Low in Calories & 2.73 & 5 & 19 \\
& 2.2 Low in Fat \& Cholesterol & 2.39 & 6 & 20 \\
& 2.3 High in Essential Minerals & 3.16 & 2 & 13 \\
& 2.4 Low in Carbohydrates & 2.78 & 4 & 17 \\
2.5 High in Protein & 3.11 & 3 & 14 \\
& 2.6 High in Vitamins & 3.21 & 1 & 12 \\
3.1 High in Purity & 4.21 & 3 & 4 \\
3.2 High in Compositional Integrity & 3.82 & 6 & 8 \\
& 3.3 Better Appearance & 4.52 & 1 & 2 \\
3.4 Better Taste & 3.89 & 5 & 7 \\
& 3.5 High Convenience & 4.42 & 2 & 3 \\
3.6 Better Size and Style & 4.06 & 4 & 5 \\
4.1 Better Package Material & 4.73 & 1 & 1 \\
4.2 Better Other Information & 3.47 & 3 & 9 \\
4.3 Better Labeling & 3.91 & 2 & 6 \\
\hline
\end{tabular}


The MSQA value and respective ranks obtained by the attributes included in the "food safety" and "nutritional" subsets suggest that their importance to the consumer in compared to the same obtained through the conventional products is "marginal" (i.e. $2.5<$ MSQA < 3.5). In two cases, i.e. "food additives" (2.36) and "cholesterol" (2.39), consumers did not agree with the fact that FMTP is better than its counterpart, since that value is less than 2.5. These suggest that consumers wish to purchase FMTP on the judgment that it is a quality product in terms of "value" and "package" attributes (e.g. purity, size, appearance, and labeling etc.), where the food processor has a much control to upkeep or enhance the status of attributes towards better. On the other hand, for the attributes where food processor has a limited control over the maintaining of quality standards with his/her own effort (e.g. foodborne pathogens, heavy metal, pesticide residues, and veterinary medicine etc.), consumers did not consider that FMTP is a far better product than fresh milk stored in those conventional types of packaging materials.

\section{Descriptive Statistics of FQRI}

Those scores provided to the 21 quality attributes by each consumer on the five-point likert-scale were next used to estimate the FSRI of a consumer. The distribution of FQRI amongst the "FMTP lovers" $(\mathrm{n}=100)$ ranged from the 0.23 (the lowest) to 0.87 (the highest) with a mean of 0.49 (Standard Deviation $=0.02$ ). The higher FQRI of a consumer (i.e. values greater than $0.5)$ indicates that his/her choice is changing from one alternative (e.g. preference for quality attributes linked to conventional packs) to another (i.e. preference of quality attributes linked with FMTP), as a whole. This tells that this consumer is willing to accept the fact that FMTP is a quality product in terms of all these attributes, on an average (because there may be a chance that he/she likes certain attributes very much, and at the same time, he/she may not prefer certain other attributes). This can be explored further using the relationship between the frequency of consumption of FMTP by a consumer and respective FQRI of the consumer (Figure 02).

It indicates that there is a strong relationship between these two factors, because the "Pearson Correlation Coefficient" between them was 0.9526 and $\mathrm{R}^{2}$ of the relationship was more than 0.9. This is a clear indication that people who purchase FMTP in higher amounts (i.e. 4 to 5 per week) are perceived optimistically on the favorable quality attributes of it over the other substitutes, and those who purchase less amount of it (i.e. 2 to 3 per week) did not much concern or indifferent with respect to favorable quality attributes of FMTP over the other substitutes.

\section{Estimates from the Ordered Logistic Regression}

The first step towards conducting the Ordered Logistic Regression analysis was to develop ordered dependent variables (Pampel, 2000). There were four dependent variables developed in this respect based on the values of FRQI that used the "lower" and "upper" limits shown in Table 04.

Table 04 illustrates that 60 percent of FMTP lovers were fallen within the dependent variables $D_{1}$ and $D_{2}$, which were developed using the FQRI values in the range of 0.23 to 0.5 . This suggests that these consumers did not recognize any significant difference between the FMTP and its substitutes 
with respect to these attributes, as a whole. Actually, this reflects the lowers ranks given by consumers to the attributes included in the food safety and nutrition sub sets. The logged odds / logits from Ordered Logistic Regression and the Marginal Probabilities estimated subsequently for the five explanatory variables are reported in Table 05 .

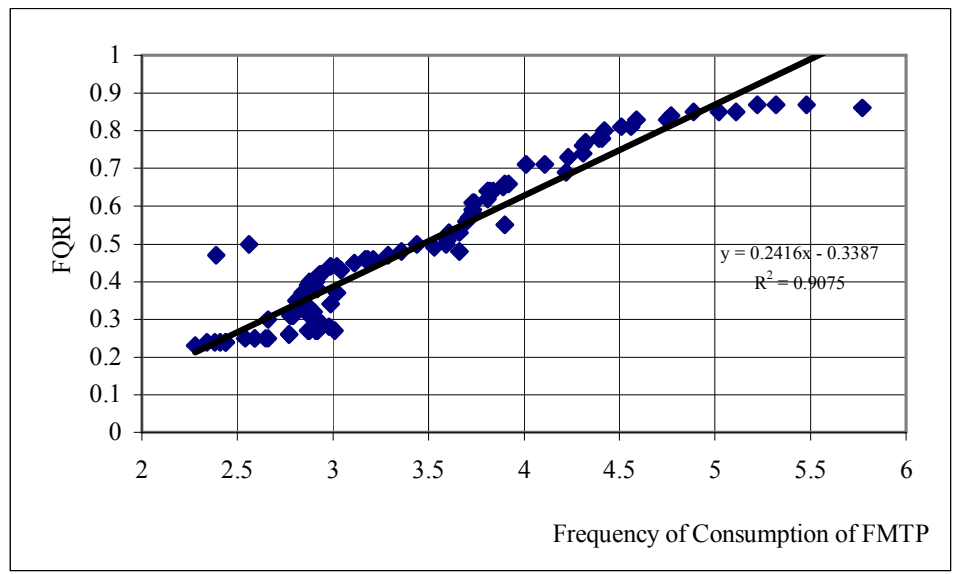

Figure 02: The relationship between frequency of consuming FMTP and FRQI

Table 04: Ordered dependent variables derived from the FQRI:

\begin{tabular}{|c|c|c|c|}
\hline \multirow{2}{*}{$\begin{array}{c}\text { Dependent } \\
\text { Variable }\end{array}$} & \multicolumn{2}{|c|}{ Limits of Ordered Variables } & \multirow{2}{*}{$\begin{array}{l}\text { No of Consumers } \\
\text { (Out of 100) }\end{array}$} \\
\hline & Lower Limit & Upper Limit & \\
\hline $\mathrm{D}_{1}$ & 0.23 & $\leq 0.36$ & 36 \\
\hline $\mathrm{D}_{2}$ & $>0.36$ & $\leq 0.50$ & 24 \\
\hline $\mathrm{D}_{3}$ & $>0.50$ & $\leq 0.64$ & 15 \\
\hline $\mathrm{D}_{4}$ & $>0.64$ & $\leq 0.87$ & 25 \\
\hline
\end{tabular}

(Note: $0.23=$ minimum value (theoretically zero) and $0.87=$ maximum value (theoretically one))

Table 05: Results from the Ordered Logistic Regression

\begin{tabular}{crcc}
\hline Variable & Estimate & Standard Error & Marginal Probability \\
\hline $\mathrm{D}=1$ & $3.3153 *$ & 1.2218 & - \\
$\mathrm{D}=2$ & $8.5122^{*}$ & 1.8146 & - \\
$\mathrm{D}=3$ & $9.2380^{*}$ & 1.8650 & - \\
$\mathrm{D}=4$ & $10.0140^{*}$ & 1.9471 & - \\
$\mathrm{AGE}$ & $-5.7311 * * *$ & 1.2195 & -0.46 \\
$\mathrm{GEN}$ & $-0.2439 * *$ & 0.7685 & -0.39 \\
$\mathrm{INC}$ & $1.4515^{* *}$ & 0.5677 & 0.24 \\
$\mathrm{EDU}$ & $-1.3183 *$ & 0.9695 & 0.17 \\
$\mathrm{MRS}$ & $0.6460 * *$ & 0.1786 & 0.44 \\
\hline (Notes: $* * *$ and $* *$ denote statistical significance at $\mathbf{1 \%}$ and 5\%.)
\end{tabular}


Interestingly, all the variables included in the model have a significant impact, to a various degree, on the consumer perceptions towards a quality of FMTP. It can be seen from the results that both the age (AGE) and the marital status (MRS) of consumers possess the highest impact (i.e. significant at $\rho=0.01$ ). In fact, the negative sign of the AGE variable explains that when people get older their preference for FMTP decreases and as expected "young" and "unmarried" consumers prefer this product. Further, the type of the sex of a consumer (SEX) and his/her disposable income as a fraction of total income (INC) showed a moderate impact (i.e. significant at $\rho=0.05$ ). This suggests that "females" and those consumers with over 0.75 of their income spend on purchasing of goods and services have tendency to purchase FMTP over other substitutes than their counterparts, i.e. "males" and those with low disposable income. Finally, the education level of consumer (EDU) shows a marginal impact (i.e. significant at $\rho=0.10$ ) indicating that consumers with a relatively higher education prefer it. In abstract, the outcome of analysis suggests that young and educated unmarried males with a higher purchasing power have a large tendency to purchase FMTP.

\section{CONCLUSIONS}

This study examines the relative importance of quality attributes included in four subsets in the Caswell's food quality attributes classification (1998) on consumer decision to purchase fresh milk stored in tetra-packs, which is one of the latest introductions to the food manufacturing industry in Sri Lanka. The majority of consumers who used to purchase this product more than 3 times a week indicate that it is a better product in terms of satisfying consumers on a number of quality attributes such as better packaging material, convenient to handle, economical size, appearance, and purity etc., which are classified under the subsets of value and package. However, those consumers, in general, did not judge that it is better in quality in terms of many attributes included in the subsets of food safety and nutrition.

The statistical outcome based on Ordered Logistic regression techniques suggest that all the variables have a significant impact, although with varied size and sign effects, where the age and marital status of the consumer, in general, has the highest impact on this behavior. More broadly, the outcome of analysis suggests that young and unmarried educated males with a relatively higher purchasing power show a large tendency to purchase FMTP based on its package and values attributes. The results suggest that food producers, in general, and processors of fresh milk, in particular, may increase their sales by introducing more innovative and differentiated products to the market such as tetra-packs. In fact, this may help to increase the consumption of milk amongst the younger generation, since the statistics show that fresh milk consumption in Sri Lanka is considerably low with the per capita consumption of about $4.14 \mathrm{Kg}$ per year and only about 1 percent of the population in the island consumes fresh milk regularly as compared to 63 percent of others consume varieties of full-cream milk powder. Also, the results indicate that market cannot make consumers "idiotic", because they judge that those containers with a greater "outlook" do not guarantee a safe and nutritious product. Thus, most incentive-based means of promoting fresh milk in terms of its quality may 
allow market to promote their products by taking into account of value and packaging attributes, and the government should take into account in regulating food safety and nutrition related attributes through appropriate food standards.

\section{References}

Borooah, V. K. (2002). Logit and Probit: Ordered and Multinomial Models. Series: Quantitative Applications in the Social Sciences. No. 138, Thousand Oaks: Sage Publication.

Brown, G. H. (1994). Measuring consumer attitudes toward products. Journal of Marketing 14 (5): pp. 691-98.

Buchanan, J. M. (1969). Cost and Choice: An Inquiry in Economic Theory. Markham. Chicago.

Caswell, J. A. (1998). Valuing the Benefits and Costs of Improved Food Safety and Nutrition. Australian Journal of Agriculture and Resource Economics. 42 (December): pp. 409-474.

Caswell, J. A. (1992). Current Information Levels on Food Labels. American Journal of Agricultural Economics. 74 (December): pp. 1196 - 1201.

Caswell, J. A. and E. M. Mojduszka. (1996). Using Informational Labeling to Influence the Market for Quality in Food Products. American Journal of Agricultural Economics. 78 (5): pp. 1248-1253.

Caswell, J. A. and D. Padberg. (1992). Towards a More Comprehensive Theory of Food Labels. American Journal of Agricultural Economics. 74(2): 460-468.

Darby, M. R., and E. Karni. (1973). Free Competition and the Optimal Amount of Fraud. Journal of Law and Economics. 16: pp. 67-88.

Frazao, E. and J. E. Allshouse. (1996). Nutritionally Improved Foods in Grocery Stores: 1989 - 93. The Economics of Reducing Health Risk from Food. J. A. Caswell (Ed.) Stores CT: Food marketing Policy Center. pp. $149-161$.

French, M. T. and D. M. Neighbors (1991). A Model of Firm Costs of Compliance with Food Labelling Regulations. In. J. A. Caswell (Ed.). Economics of Food Safety. Elsevier, New York. pp. 299-415

Garvin, D. A. (1987). Competing on the Eight Dimensions of Quality. Harvard Business Review, (November - December), pp. 101-109.

Hair, J. F., R. E. Anderson, R. L. Tatham, and W. C. Black (1995). Multivariate Data Analysis with Readings. Prentice Hall, Englewood Cliffs, New Jersey.

Hooker, N. H. and J. A. Caswell (1998). Trends in Food Quality Regulation: Implications for Processed Food Trade and Foreign Direct Investment. Agribusiness. 12(5): pp. 411-419.

Nelson, P. (1974). Advertising as Information. Journal of Political Economics. 81: pp. $729-754$.

Nelson, P. (1970). Information and Consumer Behavior. Journal of Political Economics. 78: pp. 311-329.

Oppenheim, A. N. (1992). Questionnaire Design, Interviewing and Attitude Measurement. Pinter Publishers, London.

Pampel, F.C. (2000). Logistic Regression: A Primer. Series: Quantitative Applications in the Social Sciences. No. 132, Thousands Oaks: Sage Publications.

Powers, D. A. and Y. Xie. (1999). Statistical Methods for Categorical Data Analysis. Academic Press Inc. 